\title{
Response to the emerging novel coronavirus outbreak
}

\author{
Worldwide political commitment to pandemic preparedness is essential
}

\author{
Ilona Kickbusch director ${ }^{1}$, Gabriel Leung dean of medicine ${ }^{2}$ \\ ${ }^{1}$ Global Health Programme, Graduate Institute of International and Development Studies, Geneva, Switzerland; ${ }^{2}$ Li Ka Shing Faculty of Medicine, \\ University of Hong Kong, Hong Kong SAR, China
}

The 2019 flagship report of the Global Preparedness Monitoring Board, A World at Risk, made it clear that the key question is not whether there will be a global pandemic, but when. ${ }^{1}$ While scientists and public health professionals are working non-stop to contain the novel coronavirus 2019-nCoV, political scientists, economists, and sociologists should also ready themselves for rapid response. The current outbreak that originated from Wuhan, China, first recognised barely a month ago, ${ }^{2}$ is very different from other outbreaks in terms of scale, connectivity, and political implications. It will teach us important lessons about preparedness but also about the response to outbreaks in different political systems within a new geopolitical world order.

\section{Containment measures}

The country paying the highest price is China-socially and economically, in addition to the enormous physical and mental health burden on its citizens. ${ }^{3}$ China has taken draconian measures to contain the outbreak, including the quarantine of at least 30 million residents of Wuhan and neighbouring cities. Countrywide interventions include delaying resumption of school after the spring festival holiday, encouraging citizens to work from home and stay at home, using personal protective equipment such as face masks, and cancelling all mass gatherings. Confirmed infections, whether exported directly from Wuhan or locally transmitted, are now reported in all regions of the country.

Everything about China is on a large scale, dealing in tens of millions not the hundreds or thousands that might be affected in other contexts. Never before has an infectious disease outbreak led to the shutdown of cities that are larger than many countries. The 2019-nCoV outbreak is disrupting the lives of one in five people in the world who live within China and, at the time of writing, it had already spread to 19 other countries. Imagine shutting down the European Union.

Is this a public health emergency of international concern on the grounds of scale and global connectivity alone? Arguably, yes. China is fully integrated in the global flow of goods, services, and people, and the outbreak will hurt not only global trading partners but also small Swiss villages dependent on Chinese tourists. China is restricting the travel of its population within the country, as well as not allowing Chinese tourist groups to travel abroad. One by one major airlines have suspended their services to China, and companies are shutting down offices and shops.

A new feature is that foreign countries are flying out their citizens and putting them under quarantine back home. Inequalities are emerging between those who can leave and those who cannot. People from low and middle income countries may be stranded until the metropolis wide quarantine is lifted-for example, an estimated 4600 students from more than 12 African countries are studying in Hubei province alone.

Geopolitical distrust and tensions make it difficult to cooperate and build trust during a major outbreak, and some social media content contributes to fear and misinformation or dis-information. Chinese people abroad are facing discrimination because people fear infection. The director general of the World Health Organization has expressed his respect to the Chinese political leadership for its response, stating that China's measures are protecting not only its own people but the global population. He underlines that now China needs the world's solidarity and support. This aspect is often neglected in reporting, particularly in countries traditionally suspicious of the Chinese state- the New York Times characterised President Xi as using "brutal efficiency" in outbreak control, for example.

\section{Possible consequences}

All responses to major outbreaks are deeply political. The Chinese response is now being overseen by the country's president and premier - the outcome will either strengthen or weaken their authority in the eyes of the people. But nobody knows what the fallout will be politically. A key factor is how the political tensions between the local, provincial, and national governments will play out in the long run as responses-especially the questions around the start of the outbreak-are assessed and blame distributed.

The outbreak could improve or dent China's global status. It has hit at a time when China's growth has already slowed. The country has only just emerged from difficult early trade negotiations with the US. International cooperation is essential 
but difficult, given current geopolitical tensions that include mistrust over Huawei's role in the world's $5 \mathrm{G}$ networks and recent prosecution of American scientists with paid links to Chinese laboratories and research agencies, among others.

China is still a developing country, despite rapid progress over recent decades. The outbreak has hit just as it is trying to bolster universal health coverage for all citizens. The extraordinary effort required by its authorities gives an indication of the gaps in global response that would occur if the infection spread to low and middle income countries with suboptimal surveillance and treatment infrastructure, and limited access to personal protective equipment. These problems go beyond Africa-development agencies such as the Asian Development Bank are concerned about regional economies with fragile health systems, where an epidemic could push the region into recession. ${ }^{4}$ The conditions for triggering the World Bank's pandemic emergency financing facility still had not been met on 31 January 2020 as the number of deaths is "insufficient" and local sustained transmission is confined to China.

We will need new governance instruments to supplement the international health regulations that can respond to scale, speed, and connectivity in agile ways as well as new financing instruments that support all affected countries. ${ }^{5}$ Above all, the world finally needs total political commitment to pandemic preparedness.

Competing interests: We have read and understood BMJ policy on declaration of interests and have no relevant interests to declare.

Provenance and peer review: Commissioned; not externally peer reviewed.

1 Global Preparedness Monitoring Board. Flagship report. 2019. https://apps.who.int/gpmb/ flagship_report.html

2 World Health Organization. Novel coronavirus 2019. https://www.who.int/emergencies/ diseases/novel-coronavirus-2019

3 World Health Organization. WHO, China leaders discuss next steps in battle against coronavirus outbreak. https://www.who.int/news-room/detail/28-01-2020-who-chinaleaders-discuss-next-steps-in-battle-against-coronavirus-outbreak

4 Asian Development Bank. Middle East respiratory syndrome is testing Asia's ability to address emerging diseases. https://www.adb.org/news/features/middle-east-respiratorysyndrome-testing-asia-s-ability-address-emerging-diseases

5 World Health Organization. Strengthening health security by implementing the International Health Regulations (2005) https://www.who.int/ihr/about/en/

Published by the BMJ Publishing Group Limited. For permission to use (where not already granted under a licence) please go to http://group.bmj.com/group/rights-licensing/ permissions 